\title{
UTILIZACIÓN DE PCR PARA LA IDENTIFICACIÓN DE PIROPLASMOSIS EQUINA EN UN CRIADERO DE JAMUNDÍ (COLOMBIA)
}

\section{USE OF PCR FOR THE IDENTIFICATION OF EQUINE PIROPLASMOSIS IN A FARM LOCATED IN JAMUNDÍ (COLOMBIA)}

\section{${ }^{1}$ Indrid Marcela González Jiménez, ${ }^{2}$ Fernando Favian Castro Castro, ${ }^{3}$ Fredy Javier Angarita Alonso, ${ }^{4}$ Luis Gabriel Rivera-Calderón}

\author{
'Médico Veterinaria, Universidad Antonio Nariño (UAN), Popayán, Colombia. \\ ${ }^{2}$ Médico Veterinario, Ph.D, UAN, Grupo Quirón, Popayán, Colombia. \\ ${ }^{3}$ Médico Veterinario y Zootecnista, M.Sc, UNAD, Grupo TECNOGÉNESIS. \\ ${ }^{4}$ Médico Veterinario y Zootecnista, Ph.D, UAN, Grupo GIPSA, Popayán, Colombia. \\ ${ }^{1}$ indgonzalez@uan.edu.co; ${ }^{2}$ favian.castro@uan.edu.co; \\ ${ }^{3}$ fredy.angarita@unad.edu.co; ${ }^{4}$ Igrivera@uan.edu.co
}

\section{RESUMEN}

Contextualización: la piroplasmosis equina es una enfermedad transmitida por garrapatas, causada por protozoarios de la especie Babesia caballi y Theileria equi. Los animales afectados presentan diferentes signos clínicos que incluyen anemia, fiebre, ictericia y depresión. Los equinos infectados con $T$. equi pueden ser portadores de manera vitalicia del parasito, mientras que aquellos que contraen $B$. caballi pueden diseminarlo por algunos años hasta finalmente quedar libres de la infección.

Vacío de investigación: en Colombia existen pocos estudios sobre el aislamiento e identificación de hemoparásitos en equinos mediante técnicas moleculares como reacción en cadena de la polimerasa. Dentro de estos parásitos se encuentran Babesia caballi y Theileria equi, agentes causantes de la Piroplasmosis una enfermedad de declaración obligatoria por la Organización Mundial de Sanidad Animal (OIE).

Propósito del estudio: el objetivo de este estudio fue identificar la Piroplasmosis equina mediante PCR en un criadero localizado en el municipio de Jamundí (Valle del Cauca).

Metodología: de un total de 20 ejemplares, divididos en dos grupos, (animales estabulados y animales en potrero), se colectó sangre periférica para realizar frotis teñidos con Wright. Además, se enviaron otras muestras al laboratorio para diagnóstico molecular. 
Resultados y conclusiones: todas las muestras con Wright fueron negativas a hemoparásitos, sin embargo, por PCR convencional fue posible identificar piroplasmosis. La PCR fue un método sensible y confiable para diagnosticar la enfermedad en un individuo asintomático. Más estudios deben ser realizados en esta región sobre Babesia sp., para identificar sus posibles factores predisponentes y causales, así como para mejorar las medidas de prevención, control y tratamiento.

Palabras clave: Babesia sp.; caballo; diagnóstico; garrapatas; protozoo.

\section{ABSTRACT}

Contextualization: Equine piroplasmosis is a tick-borne disease, caused by protozoa Babesia caballi and Theileria equi. The animals affected have different clinical signs that include anemia, fever, icterus and depression. Infected equids with $T$. equi can carry the hemoparasite for life, while the infected animals with $B$. caballi can disseminate for a few years until finally get rid of the infection.

Knowledge gap: In Colombia there are few studies on the isolation and identification of hemoparasites in equines using molecular techniques such as PCR. Among these parasites are Babesia caballi and Theileria equi, causative agents of Piroplasmosis a disease notifiable by the World Organisation for Animal Health.

Purpose: The aim of this study was to identify equine piroplasmosis using polymerase chain reaction in a farm located in Jamundí (Valle del Cauca).

Methodology: In a total of 20 animals, divided in two groups, (animals in stable and animals in grassland) was collected peripheral blood to perform smear stained with Wright. Also, other samples were sent to the laboratory for molecular diagnosis.

Results and conclusions: All samples with Wright were negative for hemoparasites, however, by PCR it was possible to identify piroplasmosis. Conventional PCR was a sensitive and reliable method to diagnose the disease in an asymptomatic individual. More studies should be carried out in this region on Babesia sp. to identify possible predisposing and causal factors, as well as to improve the measures for its prevention, control and treatment.

Keywords: Babesia sp; horse; diagnosis; ticks; protozoon.

\section{Resumen gráfico}

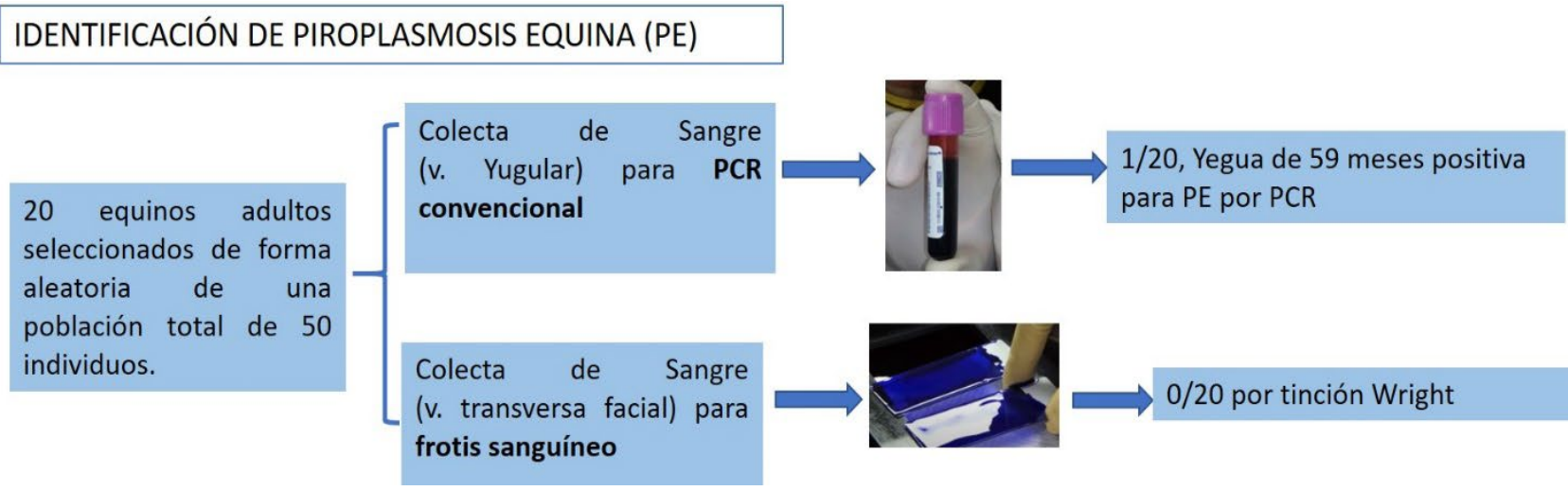




\section{INTRODUCCIÓN}

La piroplasmosis equina (PE) es una enfermedad producida por protozoarios de la especie Babesia caballi y Theileria equi, transmitida principalmente por garrapatas de los géneros Hyalomma sp., Rhipicephalus sp. y Dermacentor $\mathrm{sp}$. Otras formas de infección reportadas son las agujas contaminadas o transfusiones sanguíneas (Gray, Estrada-Peña y Zintl, 2019; Onyiche et al., 2019).

Existen cuatro formas de presentación de esta enfermedad: hiperaguda, aguda, subaguda y crónica. La de mayor frecuencia es la PE aguda, en la cual, los animales presentan fiebre, inapetencia, disnea, taquipnea, malestar y congestión en las mucosas. En los casos crónicos, los signos clínicos incluyen inapetencia leve, baja tolerancia al ejercicio, fiebre transitoria y pérdida de peso (OIE, 2018; Onyiche et al., 2019). La PE causa pérdidas económicas importantes en la industria equina, debido a los costos en su control y tratamiento, abortos en yeguas infectadas o la muerte de animales que presentan cuadros hiperagudos o agudos. Además, las yeguas infectadas (incluidas las portadoras), pueden transmitir $T$. equi a sus crías, las cuales, a su vez, pueden nacer con anemia o ser portadores sanos (Georges et al., 2011).

La enfermedad ha sido reportada en Asia, África, América central, América del sur, en el sur de Europa y Estados Unidos (OIE, 2018). En Colombia algunos autores han informado la presencia de Babesia sp. en tres departamentos (Córdoba, Sucre y Antioquia), pero la situación epidemiológica en el país de PE sigue siendo desconocida, debido a la ausencia de estudios que identifiquen los vectores incriminados en la transmisión (Benavides y Rodríguez, 2009; Calderón, Cardona y Vergara, 2013; Agudelo-Ruíz et al., 2017; Strauch et al., 2018).
Según la OIE (2018) existen diferentes técnicas para diagnosticar $B$. caballi y $T$. equi, cada una con un propósito; por ejemplo, demostrar la ausencia de la infección en una población, confirmar casos clínicos o contribuir a las políticas de erradicación. Entre las técnicas utilizadas para la detección de PE se encuentran la tinción tipo Romanovsky en frotis sanguíneo, inmunofluoresencia indirecta (IFA), enzimoinmunoanálisis de competición (C-ELISA), y PCR dirigida al gen de la subunidad $18 S$ de ARNr.

El objetivo de este estudio fue identificar PE en un criadero de caballos de raza paso fino colombiano en el municipio de Jamundí, mediante la utilización de coloración con Wright en frotis sanguíneo y PCR convencional.

\section{MATERIALES Y MÉTODOS}

Este estudio se realizó en un criadero equino ubicado en las coordenadas $3^{\circ} 15^{\prime} 39^{\prime \prime} \mathrm{N}$ $76^{\circ} 32^{\prime} 22^{\prime} O$ del municipio de Jamundí, Valle del Cauca, a una altura de 869 m.s.n.m. Las condiciones climáticas durante el desarrollo del experimento fueron: temperatura promedio de $24{ }^{\circ} \mathrm{C}$, humedad relativa del $90 \%$ y precipitación media mensual de $90 \mathrm{~mm}$.

Se seleccionaron 20 equinos de forma aleatoria, de una población total de 50 animales que se encontraban en el criadero. Los ejemplares escogidos se dividieron en dos grupos: 10 alojados en pesebreras (Grupo 1); y 10 se encontraban en potrero (Grupo 2). La alimentación de los animales estabulados era con ración, y los de potrero recibían ración y consumían pasto estrella (Cynodon plectotachyus). Cabe mencionar que todos los animales en el área de estudio contaban con el plan vacunal exigido en el país. 
Luego de la identificación de los animales, se realizó un examen físico, evaluando su condición corporal según la escala de Henneke et al., (1983) y constantes fisiológicas. Las muestras de los animales seleccionados se tomaron en horas de la mañana. La sangre extraída de la vena transversa facial se utilizó para frotis en portaobjetos teñidos con Wright, siguiendo el protocolo de Calderón, Cardona y Vergara (2013). Los portaobjetos se analizaron en el Laboratorio de Ciencias Básicas de la Universidad Antonio Nariño, Popayán. Por su parte, las muestras colectadas de la vena yugular fueron enviadas en una caja térmica a $4{ }^{\circ} \mathrm{C}$ al laboratorio de Biología Molecular de la Facultad de Ciencias Agrarias de la Universidad de Antioquia, Medellín.

En el Laboratorio se hizo el aislamiento del
ADN de la sangre colectada, usando un kit para sangre (QIAGEN Inc., Valencia, CA, USA), siguiendo las recomendaciones del fabricante. Para la técnica de PCR convencional, la mezcla de reacción se efectuó en un volumen final de $50 \mu \mathrm{L}$, con solución tampón de amplificación (10 mM Tris $\mathrm{HCl}(\mathrm{pH} \mathrm{8,0),50} \mathrm{mM} \mathrm{KCl} \mathrm{y} 1,5 \mathrm{mM}$ $\mathrm{MgCl}_{2}$ ), además de $3 \mu \mathrm{L}$ de ADN molde, $2 \mathrm{mM}$ de dNTPs, 2,5 pmol de cada primer universal (Tabla 1) y 2,5 U de AmpliTaq Gold (Applied Biosystems, Tokio, Japón). En el termociclador se repitieron 40 ciclos con los siguientes pasos: desnaturalización durante 1 minuto a 96 ${ }^{\circ} \mathrm{C}$; anillamiento durante 1 minuto a $60,5^{\circ} \mathrm{C}$; extensión durante 1 minuto a $72^{\circ} \mathrm{C}$; y extensión final durante 10 minutos a $72^{\circ} \mathrm{C}$. La visualización de los productos de PCR se realizó por electroforesis en gel agarosa al 1,5\% teñidos con bromuro de etidio (Figura 1).

Tabla 1. Primers universales utilizados en PCR para el diagnóstico de Piroplasmosis Equina.

\begin{tabular}{|l|l|l|l|}
\hline Nombre de parásito & Primers & secuencia & Número de pares de bases \\
\hline Theileria equi & Bec-UF1-F & $5^{\prime}$-GTTGATCCTGCCAGTAGTCA-3' & 913 bp \\
\hline & Bec-UR-R & $5^{\prime}$-CGGTATCTGATCGTCTTCGA-3' & \\
\hline Babesia caballi & Bec-UF1-F & $5^{\prime}$-GTTGATCCTGCCAGTAGTCA-3' & 867 bp \\
\hline & Bec-UR-R & $5^{\prime}$-CGGTATCTGATCGTCTTCGA-3' & \\
\hline
\end{tabular}

Fuente: autores

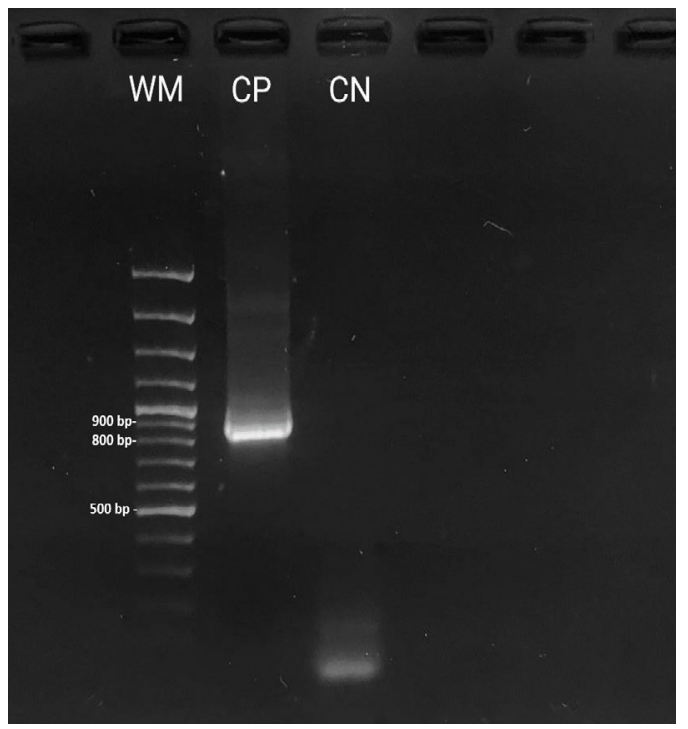

Figura 1. Electroforesis de la PCR con controles para Piroplasmosis equina. En este estudio se utilizaron Primers universales para Theileria equi y Babesia caballi, con productos de PCR de 913 bp y 867 bp, respectivamente. Debido a la pequeña diferencia del tamaño entre las bandas, no es posible distinguirlas usando un gel de agarosa, por lo que se reporta el resultado como positivo para piroplasmosis sin especificar el género causal. WM= Marcador, $C P=$ Control positivo, $\mathrm{CN}=$ Control negativo.

Fuente: autores 


\section{Análisis Estadístico}

Se utilizó un análisis estadístico descriptivo para caracterizar la población muestreada; y luego se determinaron porcentajes, medidas de tendencia central y medidas de dispersión en las variables cualitativas (sexo y presencia de garrapatas) y cuantitativas (edad y condición corporal). Las tablas y gráficos para la obtención e interpretación de los resultados se elaboraron en una hoja de Microsoft Excel.

\section{RESULTADOS Y DISCUSIÓN}

Gray, Estrada-Peña y Zintl (2019), determinaron que la Babesia caballi y la Theileria equi, son dos protozoos intra-eritrocitarios causantes de la babesiosis y theileriosis equina. Para Wise et al., (2014), estas dos enfermedades en conjunto también son conocidas como Piroplasmosis equina y se pueden transmitir por garrapatas o de forma iatrogénica. Además, Rothschild y Knowles (2007), señalan que estos protozoarios son capaces de infectar también a mulas, burros y cebras, caracterizándose clínicamente por una anemia hemolítica aguda.

En este estudio se seleccionó el $40 \%$ de la población de un criadero para muestreo sanguíneo con el fin de identificar PE. El promedio de edad de los machos que se analizaron fue de 76 meses, mientras que el de las hembras fue de 88 meses. En el examen clínico, todos los animales presentaron constantes fisiológicas normales, buena condición corporal y ausencia de ectoparásitos.

La frecuencia de Babesia sp., fue del $0 \%(0 / 20)$, con la tinción de Wrigth. Diferentes autores reportan frecuencias bajas para esta enfermedad cuando se utiliza la tinción de Wrigth. Así, Calderón, Cardona y Vergara (2013) reportan una prevalencia de 18,25\%, De Vera et al.,
(2006) $13,1 \%$ y Castellanos et al., (2010) 1,4 \% para Babesia sp. Las tinciones sanguíneas permiten la identificación del parásito mediante el microscopio óptico, especialmente en la fase aguda de la enfermedad; sin embargo, es muy difícil su detección por frotis en animales portadores crónicos o inaparentes (Krause, 2003; De Vera et al., 2006).

Por otro lado, durante la fase aguda de la infección, los parásitos en sangre pueden mantenerse en niveles bajos que se relacionan como falsos negativos (Friedhoff y Soulé, 1996), especialmente para $B$. caballi, con parasitemias que pueden llegar al 0,1\% (Wise et al., 2013). Cabe destacar, que las pruebas sanguíneas presentan baja sensibilidad en comparación con las pruebas moleculares como la PCR (Rampersad et al., 2003; Alhassan et al., 2005; Ibrahim et al., 2011; Malekifard et al., 2014). En esta investigación un animal negativo a Babesia sp. en frotis sanguíneo teñido con Wright, resultó positivo por PCR convencional. Se trataba de una yegua de 59 meses de edad, estabulada y con condición corporal 8/10 (Tabla 2 y Tabla 3). Respecto a la variable sexo, en un estudio realizado con équidos (caballos, asnos y mulas) se reportó que la frecuencia de infección en las hembras fue de $55,5 \%$, mientras que en los machos de $45,5 \%$, para un total de 18 animales infectados (Agudelo-Ruíz et al., 2017).

De acuerdo con Böse et al., (1995), la sensibilidad del PCR es unas 100 veces superior a la de las técnicas microscópicas, detectando el ADN del parásito en una sangre con una parasitemia de $10^{-9}$, que se traduce en la detección de un parásito por cada 1.000.000.000 eritrocitos. Igualmente, los resultados con PCR son confiables si la cantidad de ADN a detectar es muy pequeña (1 picogramo, es decir, $10^{-12}$ gramos de ADN). 
Tabla 2. Categorización de los animales según las variables definidas para el estudio.

\begin{tabular}{|c|c|c|c|c|c|c|c|c|}
\hline $\begin{array}{l}\text { Número } \\
\text { del caso }\end{array}$ & $\begin{array}{c}\text { Edad } \\
\text { (meses) }\end{array}$ & Sexo & C.C & Localización & $\begin{array}{l}\text { Constantes } \\
\text { Fisiológicas }\end{array}$ & $\begin{array}{c}\text { Presencia de } \\
\text { Garrapatas }\end{array}$ & $\begin{array}{l}\text { Tinción } \\
\text { Wright } \\
\text { para PE }\end{array}$ & $\begin{array}{c}\text { PCR } \\
\text { convencional } \\
\text { para PE }\end{array}$ \\
\hline 1 & 70 & $\mathrm{H}$ & 8 & $E$ & $\mathrm{~N}$ & No & - & - \\
\hline 2 & 68 & $\mathrm{H}$ & 9 & $E$ & $\mathrm{~N}$ & No & - & - \\
\hline 3 & 59 & $\mathrm{H}$ & 8 & $E$ & $\mathrm{~N}$ & No & - & + \\
\hline 4 & 72 & $\mathrm{H}$ & 8 & $E$ & $\mathrm{~N}$ & No & - & - \\
\hline 5 & 83 & $M$ & 9 & $E$ & $\mathrm{~N}$ & No & - & - \\
\hline 6 & 91 & $\mathrm{H}$ & 9 & $E$ & $\mathrm{~N}$ & No & - & - \\
\hline 7 & 47 & $M$ & 9 & $E$ & $\mathrm{~N}$ & No & - & - \\
\hline 8 & 53 & $\mathrm{H}$ & 8 & $E$ & $\mathrm{~N}$ & No & - & - \\
\hline 9 & 98 & $M$ & 8 & $E$ & $\mathrm{~N}$ & No & - & - \\
\hline 10 & 87 & $\mathrm{H}$ & 9 & $E$ & $\mathrm{~N}$ & No & - & - \\
\hline 11 & 130 & $\mathrm{H}$ & 8 & $P$ & $\mathrm{~N}$ & No & - & - \\
\hline 12 & 99 & $\mathrm{H}$ & 8 & $P$ & $\mathrm{~N}$ & No & - & - \\
\hline 13 & 85 & $\mathrm{H}$ & 7 & $P$ & $\mathrm{~N}$ & No & - & - \\
\hline 14 & 79 & $\mathrm{H}$ & 8 & $\mathrm{P}$ & $\mathrm{N}$ & No & - & - \\
\hline 15 & 123 & $\mathrm{H}$ & 8 & $P$ & $\mathrm{~N}$ & No & - & - \\
\hline 16 & 110 & $\mathrm{H}$ & 8 & $P$ & $\mathrm{~N}$ & No & - & - \\
\hline 17 & 109 & $\mathrm{H}$ & 9 & $\mathrm{P}$ & $\mathrm{N}$ & No & - & - \\
\hline 18 & 99 & $\mathrm{H}$ & 8 & $\mathrm{P}$ & $\mathrm{N}$ & No & - & - \\
\hline 19 & 74 & $\mathrm{H}$ & 8 & $P$ & $\mathrm{~N}$ & No & - & - \\
\hline 20 & 86 & $\mathrm{H}$ & 7 & $\mathrm{P}$ & $\mathrm{N}$ & No & - & - \\
\hline
\end{tabular}

C. $\mathrm{C}=$ condición corporal; $\mathrm{M}=$ Macho; $\mathrm{H}=$ Hembra; $\mathrm{E}=$ Estabulado; $\mathrm{P}=$ Potrero; $\mathrm{N}=$ Normales.

Fuente: autores

Tabla 3. Promedio y desviación estándar de la edad y condición corporal de los equinos evaluados.

\begin{tabular}{l|c|c|c} 
& Edad & C.C & \% animal según sexo \\
\hline Promedio Total & 86,1 & 8,2 & 15 \\
\hline Promedio Macho & 76 & 8,66 & 85 \\
\hline Promedio Hembra & 87,88 & 8,11 & \\
\hline Desviación estándar Total & 22,04 & 0,61 & 0,57 \\
\hline Desviación estándar Macho & 26,21 & 0,6 & \\
\hline Desviación estándar Hembra & 21,65 & & \\
\hline
\end{tabular}

Fuente: autores 
En Colombia se han realizado pocos trabajos sobre la presencia de PE (Calderón, Cardona y Vergara, 2013; Agudelo-Ruíz et al., 2017; Strauch et al., 2018). Agudelo-Ruíz et al., (2017), observaron una frecuencia de infección de PE del 13\% (18/135), identificando por primera vez la circulación de $T$. equi en el país, en animales procedentes de Antioquía y Córdoba. En este estudio, solo fue posible identificar el género Babesia sp. mediante la técnica PCR, debido a que no se utilizaron primers específicos para diferenciar las especies que producen la PE. Por su parte, Calderón, Cardona y Vergara (2013) tomaron 126 muestras para determinar la presencia de Babesia sp., con coloración de Wright, de las cuales, el $18,25 \%$ de las muestras resultaron positivas. Dentro de ese porcentaje, observaron que los animales estabulados eran los que más se encontraban infectados, en comparación con los semi-estabulados y de potrero, a pesar de no encontrar garrapatas dentro de los grupos analizados. Los resultados de ese trabajo se asemejan con las características encontradas en el animal positivo del presente estudio (ver Tabla 2).

García et al., (2013), determinaron que existe mayor seroprevalencia de $T$. equi cuando hay presencia de garrapatas en los animales muestreados. Strauch et al., (2018) identificaron que 28 de 980 caballos muestreados poseían garrapatas $y$, de estos, solamente cuatro fueron positivos para piroplasmosis. Según estos autores, deben existir otras formas de transmisión para la PE en Colombia y agregan que existen factores de riesgo como la positividad a Anemia Infecciosa Equina y la presencia de endoparásitos (Estróngilos u Oxiuros).

Por su parte, Mantran, Votion y Amory (2004), indican que la presencia de esta enfermedad en climas cálidos es baja; sin embargo, se puede incrementar por el transporte de los equinos desde zonas donde hay registro de la enfermedad (Sigg et al. 2010). En el área de investigación, se relaciona una población alta de équidos y una gran frecuencia de eventos deportivos con asistencia considerable por parte de los criaderos que favorecerían la transmisión de PE.

En este estudio, se evidenció la presencia de PE mediante la técnica de PCR convencional en un criadero con 50 animales, esto significa que existe riesgo de infección para otros animales. Se sugiere seguir lo que ordena la autoridad sanitaria colombiana (Instituto Colombiano Agropecuario, ICA) y el código sanitario para animales terrestres de la Organización Mundial de Sanidad Animal (capítulo 12.7) (OIE, 2019), con el fin de prevenir la diseminación de la enfermedad entre animales que se muevan de una región a otra, o que participan en eventos ecuestres y generan riesgo epidemiológico.

La positividad del animal impide su exportación, su participación en competencias o su reproducción. Aún son necesarios más estudios en Colombia que permitan comprender los factores de riesgo y causales de esta enfermedad, igualmente generar trabajos a nivel de diagnóstico de métodos directos e indirectos para establecer programas de prevención y control.

\section{CONCLUSIONES}

La técnica de PCR convencional proporciona una metodología válida para identificar individuos asintomáticos con $\mathrm{PE}$, que resultan negativos a pruebas directas como los frotis sanguíneos teñidos con Wright. Para determinar el estatus sanitario de la población equina frente a la Piroplasmosis, la prueba indirecta de PCR permite generar validaciones epidemiológicas que pueden ayudar a fortalecer programas de control y prevención frente a esta enfermedad. 


\section{CONTRIBUCIÓN DE LA AUTORÍA}

Primer autor: metodología, investigación, análisis de datos, conceptualización, escritura - borrador original. Segundo autor: investigación, conceptualización, escritura - revisión y edición. Tercer autor: investigación, conceptualización, escritura - revisión y edición. Cuarto autor: investigación, análisis de datos, conceptualización, escritura - borrador original, revisión y edición.

\section{AGRADECIMIENTOS}

Al personal del laboratorio de Biología Molecular de la Facultad de Ciencias Agrarias, Universidad de Antioquia, por el procesamiento de muestras y la realización de la técnica de PCR convencional. Igualmente, a la Universidad Antonio Nariño por brindarnos un espacio en el laboratorio de Ciencias Básicas para analizar las muestras de frotis sanguíneo teñidas con Wright.

\section{LITERATURA CITADA}

Agudelo-Ruíz, Y., Acevedo-Gutiérrez, L., MontoyaSanchéz, A., Paternina, L., y Rodas, J. (2017). Molecular identification of tick-borne hemoparasites in equines from Northwestern Colombia. Revista MVZ Córdoba, 22, 6004-6013. https:// doi.org/10.21897/rmvz.1070

Alhassan, A., Wilawan, P., Okamura, M., Hirata, H., Battsetseg, B., Fujisaki, K., Yokojama, N., y Igarashi, I. (2005). Development of a single-round and multiplex PCR method for the simultaneous detection of Babesia caballi and Babesia equi in horse blood. Veterinary parasitology, 129, 43-49. https://doi.org/10.1016/j.vetpar.2004.12.018

Benavides, E., y Rodríguez, L.E. (2009). Epidemiology and control of illnesses anemic and feverish in the horses in Colombia. Revista SPEI Domus, 5(11), 20-31. Recuperado de: Recuperado de https://revistas.ucc.edu.co/index.php/sp/article/ view/593

Böse, R., Jorgensen, W.K., Dalgliesh, R.J., Friedhoff, K.T. y de Vos, A.J. (1995). Current state and future trends in the diagnosis of babesiosis", Veterinary Parasitology, 57(1-3),61-74. https://doi. org/10.1016/0304-4017(94)03111-9
Calderón, A., Cardona, J., y Vergara O. (2013). Frecuencia de Babesia spp. en caballos de montería, Córdoba (Colombia). Revista U.D.C.A. Actualidad \& Divulgación Científica, 16(1): 451-458. https:// doi.org/10.31910/rudca.v16.n2.2013.918

Castellanos, R.; Canelón, J.L.; Calzolaio, V.; Aguinaco, F.; López, Á. y Montesinos, R. (2010). Estudio hematológico y detección de hemoparásitos en caballos criollos venezolanos de dos hatos del Estado Apure, Venezuela. Revista científica de veterinaria. 20(2):153-160.

De Vera, M., Guillén, A.T., García, F., Contreras, R., Sierralta, A. y León, E. (2006). Seroprevalencia de la babesiosis equina en caballos purasangre de carrera alojados en los hipódromos de la Rinconada y Nacional de Valencia, Venezuela", Veterinaria Tropical, 31(1-2), 43-52.

Friedhoff, K.T. y Soulé, C. (1996). An account on equine babesiosis. Revue Scientifique et Technique (International Office of Epizootics), 15(3), 11911201. https://doi.org/10.20506/rst.15.3.972

García, B.I., Arenas, M.A., Hernández, E., Adaszek, L.; Carbonero, A., Almeira, S., Téllez, J.A., Palomino, G.P. y Arenas, A. (2013). Seroprevalence and risk factors associated with Babesia caballi and Theileria equi infection in equids. Veterinary Journal. 195(2):172-178. https://doi. org/10.1016/j.tvjl.2012.06.012

Georges, K.C., Ezeokoli, C.D., Sparagano O., Pargass I., Campbell, M., D'Abadie, R., y Yabsley, M.J. (2011). A case of transplacental transmission of Theileria equi in a foal in Trinidad. Veterinary Parasitology, 175(3-4), 363-366. https:// doi.org/10.1016/j.vetpar.2010.10.019

Gray, J.S., Estrada-Peña, A., y Zintl, A. (2019). Vectors of Babesiosis. Annual review of entomology, 64, 149-165. https://doi.org/10.1146/annurevento-011118-111932

Henneke, D.R., Potter, G.D., Kreider, J.L. y Yeates, B.F. (1983). Relationship between condition score, physical measurements and body fat percentage in mares. Equine Veterinary journal, 15(4): 371372. https://doi.org/10.1111/j.2042-3306.1983. tb01826.x

Ibrahim, A.K., Gamil, I.S., Abd-El baky, A.A., Hussein, M.M. y Tohamy, A.A. (2011). Comparative molecular and conventional detection methods of Babesia equi (B. equi) in Egyptian equine. Global Veterinaria, 7(2), 201-210. Recuperado de https://www.idosi.org/gv/GV7(2)11/18.pdf 
Krause, P.J. (2003). Babesiosis diagnosis and treatment. Vector Borne and Zoonotic Diseases, 3(1), 45-51. https://doi. org/10.1089/153036603765627451

Malekifard, F., Tavassoli, M., Yakhchali, M., y Darvishzadeh, R. (2014). Detection of Theileria equi and Babesia caballi using microscopic and molecular methods in horses in suburb of Urmia, Iran. Veterinary Research Forum, 5(2), 129-133. Recuperado de http://vrf.iranjournals.ir/article_5397.html

Mantran, A., Votion, D.M. y Amory, H. (2004). Piroplasmosis: A problem in Belgium? In: Proc. Annual Congress Belgian Equine Practitioners Society, Liege, Belgium. Recuperado de https://www.ivis.org/library/beps/beps-annualstudy-days-brussels-2004/piroplasmose-uner\%C3\%A9alit\%C3\%A9-belge

Organización Mundial de Sanidad Animal (OIE). (2018). Manual de las Pruebas de Diagnóstico y de las Vacunas para los Animales Terrestres 2019. Recuperado de https://www.oie.int/es/ normas/manual-terrestre/acceso-en-linea/

Organización Mundial de Sanidad Animal (OIE). (2019). Código Sanitario para los Animales Terrestres 2019. Recuperado de https://www.oie. int/index.php?id=169\&L=2\&htmfile=chapitre equine_piroplasmosis.htm\#article_equine_piroplasmosis. 2.
Onyiche, T.E., Suganuma, K., Igarashi, I., Yokoyama, N., Xuan, X., y Thekisoe. O. (2019). A Review on Equine Piroplasmosis: Epidemiology, Vector Ecology, Risk Factors, Host Immunity, Diagnosis and Control. International of Environmental research and public health, 16(10). http://doi. org/10.3390/ijerph16101736

Rampersad, J., Cesar, E., Campbell, M.D., Samlal, M. y Ammons, D. (2003). A field evaluation of PCR for the routine detection of Babesia equi in horses. Veterinary Parasitology, 114(2), 81-87. http://doi.org/10.1016/s0304-4017(03)00129-8

Sigg, L., Gerber, V., Gottstein, B., Doherr, M.G. y Frey, C.F. (2010). Seroprevalence of Babesia caballi and Theileria equi in the Swiss horse population. Parasitol. Int. 59(3):313-317. http://doi. org/10.1016/j.parint.2010.02.005

Strauch, A., Castillo, V., Piedrahita, D., Chaparro, J., Villar, D., Sánchez, A., Tobón, J., Ortiz, D., Ramírez, N. y Olivera-Ángel, M. (2018). Prevalencia de Babesia caballi, Theileria equi y tripanosomiasis y análisis de factores de riesgo en equinos de Antioquia, Colombia. Revista U.D.C.A. Actualidad \& Divulgación Científica, 21 (2), 491-500. https:// doi.org/10.31910/rudca.v21.n2.2018.976

Wise, L.N., Kappmeyer, L.S., Mealey, R.H. y Knowles, D.P. (2013). Review of equine piroplasmosis. Journal of Veterinary International Medicine. 27(6), 1334-1346. https://doi.org/10.1111/ jvim.12168
Conflicto de Intereses Los autores declaran no tener ningún conflicto de intereses.

El comité de ética respectivo, avaló el estudio presentado aquí.

\section{(9) $(9 \odot$}


